\title{
Communication
}

\section{The Association of Kinesiophobia and Pain Catastrophizing with Pain-Related Disability and Pain Intensity in Obesity and Chronic Lower-Back Pain}

\author{
Giorgia Varallo ${ }^{1,2, *(\mathbb{D})}$, Emanuele Maria Giusti ${ }^{1,2}$, Federica Scarpina ${ }^{3,4}$, Roberto Cattivelli ${ }^{1,2}$, Paolo Capodaglio ${ }^{5,6}$ \\ and Gianluca Castelnuovo ${ }^{1,2}$ (D)
}

1 Department of Psychology, Catholic University of Milan, 20123 Milan, Italy; EmanueleMaria.Giusti@unicatt.it (E.M.G.); r.cattivelli@auxologico.it (R.C.); gianluca.castelnuovo@unicatt.it (G.C.)

2 Istituto Auxologico Italiano, IRCCS, Laboratorio di Psicologia, Ospedale S. Giuseppe, 28824 Piancavallo (Verbania), Italy

3 "Rita Levi Montalcini" Department of Neurosciences, University of Turin, 10124 Turin, Italy; f.scarpina@auxologico.it

4 Istituto Auxologico Italiano, IRCCS, U.O. di Neurologia e Neuroriabilitazione, Ospedale S. Giuseppe, 28824 Piancavallo (Verbania), Italy

5 Istituto Auxologico Italiano, U.O. di U.O. Riabilitazione Osteoarticolare, Ospedale S. Giuseppe, 28824 Piancavallo (Verbania), Italy; p.capodaglio@auxologico.it

6 Department of Surgical Sciences, Physical and Rehabilitation Medicine, University of Turin, 10121 Turin, Italy

* Correspondence: giorgia.varallo@unicatt.it; Tel.: +39-338-94-84-148

Citation: Varallo, G.; Giusti, E.M.; Scarpina, F.; Cattivelli, R.; Capodaglio, P.; Castelnuovo, G. The Association of Kinesiophobia and Pain Catastrophizing with Pain-Related Disability and Pain Intensity in Obesity and Chronic Lower-Back Pain. Brain Sci. 2021, 11, 11. https:// dx.doi.org/10.3390/brainsci11010011

Received: 25 November 2020

Accepted: 22 December 2020

Published: 24 December 2020

Publisher's Note: MDPI stays neutral with regard to jurisdictional claims in published maps and institutional affiliations.

Copyright: $\odot 2020$ by the authors. Licensee MDPI, Basel, Switzerland. This article is an open access article distributed under the terms and conditions of the Creative Commons Attribution (CC BY) license (https:/ / creativecommons.org/ licenses/by/4.0/).

\begin{abstract}
Individuals affected by chronic lower-back pain and obesity have an increased risk of long-lasting disability. In this study, we aimed to explore the contribution of kinesiophobia and pain catastrophizing in explaining pain intensity and pain-related disability in chronic lower-back pain associated to obesity. A cross-sectional study on 106 participants with obesity and chronic lower-back pain was performed. We assessed pain intensity, pain disability, pain catastrophizing, and kinesiophobia levels through self-reporting questionnaire. Hierarchical regressions were performed to assess the role of pain catastrophizing and kinesiophobia on pain intensity and pain disability. According to the results, kinesiophobia, but not pain catastrophing, significantly explained both pain intensity and pain-related disability. Kinesiophobia might play a significant role in enhancing pain-related disability and the pain intensity in individuals with chronic lower-back pain and obesity. We encourage future studies in which beliefs and cognition towards pain might be a therapeutic target in interdisciplinary pain management interventions.
\end{abstract}

Keywords: obesity; chronic lower-back pain; disability; pain perception; kinesiophobia; pain catastrophizing

\section{Introduction}

Obesity is a public health issue of increasing importance [1] with substantial personal, community, and financial burdens globally [1]. It is strongly related to lower levels of physical and emotional well-being [2], and higher levels of mobility disability [3], especially when associated with other clinical conditions, including pain-related conditions [4]. Specifically, obesity is a risk factor for chronic lower-back pain (CLBP) [5], a clinical condition characterized by persistent pain (more than 3 months), in absence of a recognizable mechanical origin [6]. Obesity and CLBP share a high comorbid burden [5,7]. Affected individuals face profound functional and physical limitations [8]. Moreover, they generally report a high degree of pain-related disability in daily life [9]. The relationship between obesity and pain is complex and multifactorial [10]; evidence indicates that it might involve a combination of systemic inflammation, musculoskeletal overload, and autonomic dysreg- 
ulation [10-12]. Also, psychological factors have to be taken into account as contributing to the issue $[13,14]$.

There is an ongoing debate about which individual components might affect pain intensity and the perceived level of disability. Pain perception seems to be influenced by several factors, including emotions and cognition towards pain symptoms [15]. Within this debate, growing relevance was assumed by the fear-avoidance model [16,17], according to those individuals who experience acute pain may become trapped in a vicious circle of chronic disability and suffering, because of individual cognitive and affective responses towards pain [18-20]. Also, maladaptive behavioral coping strategies (i.e., avoidance behaviors) seem to be related to cognitive and affective responses towards pain [21], such as catastrophizing and kinesiophobia. Pain catastrophizing is defined as a set of exaggerated and negative cognitive-emotional responses to actual or anticipated painful sensations [21], leading individuals to magnify or exaggerate the threat of pain stimuli and to feel helpless because of it [22]. Kinesiophobia is an excessive, irrational, and debilitating fear towards physical movement and activity resulting from a feeling of vulnerability due to a painful injury or fear of reinjury $[23,24]$. Even though these behaviors may be adaptive in the case of acute pain, nevertheless they seem to be dysfunctional when the painful condition becomes chronic. Indeed, they might contribute to perpetuating physical activity aversion, thereby worsening mobility, pain severity, aggravating disability, and lowering the pain threshold $[10,13,25]$. Vincent and colleagues [26] suggested that, in the case of CLBP, those individuals affected by obesity reported higher levels of kinesiophobia in comparison with individuals with a healthy weight. Moreover, higher levels of kinesiophobia predicted higher levels of perceived disability [26]. Similarly, high levels of pain catastrophizing were reported to be associated with higher levels of pain related disability and pain intensity [27]. Despite these preliminary results, research about the role of kinesiophobia and pain catastrophizing in relation to pain intensity and pain-related disability in individuals with CLBP and obesity is still in its infancy.

To the aim to clarify this issue, in the present cross-sectional study, we aimed to assess the role of kinesiophobia and pain catastrophizing as predictive factors for pain-related disability and pain intensity in a sample of individuals affected by both obesity and CLBP.

\section{Materials and Methods}

A cross-sectional study was performed. One hundred and six individuals were consecutively recruited, from 1 September 2018 to 31 July 2019, at the beginning of a monthlong hospitalization for weight loss and physical therapy, at the Istituto Auxologico Italiano, U.O. di Riabilitazione Osteoarticolare, Ospedale S. Giuseppe, Piancavallo, Italia. Data were collected during the first week of diagnostic assessment, prior to the start of physical therapy and nutritional rehabilitation for weight loss. A priori sample size was estimated using G.Power (version 3.1.9.4) [28] setting a medium effect size (0.15), an alpha of 0.05 and a power of 0.80 , resulting in 92 participants. Inclusion criteria were: age in years $\leq 70$; obesity, according to a body mass index (i.e., BMI computed as the weight in kilograms divided by the square of height in meters, $\left(\mathrm{kg} / \mathrm{m}^{2}\right) \geq 30$ ) [29]; CLBP, defined as low back pain duration $>3$ months [30].

Exclusion criteria were physical or mental inability to provide signed informed consent; acute LBP or LBP duration < 3 months; specific LBP conditions (diagnosis of fracture, neoplasia, bone metastasis, stenosis); neurogenic or radicular condition; neurological disease; diagnosis of another disease that may explain lumbar pain; post-operative pain.

\subsection{Measures}

The main outcomes were assessed as follows:

- Numerical Pain Rating Scale (NPRS) was used to assess the individual's perception of pain intensity, through an 11-point scale (anchors of $0=$ no pain, $10=$ worst possible pain). The NPRS measure is an established, well-accepted outcome for chronic pain 
conditions [31]. This scale is a reliable and valid measurement instrument for assessing pain intensity [31], also in the case of chronic conditions [30].

- The Italian validation of the Roland-Morris Disability Questionnaire (RMDQ) [32], was used to assesses LBP-related physical disability. The RMDQ includes 24 dichotomous items covering daily tasks that participants have difficulty performing due to LBP. A total RMDQ score ranging from 0 to 24 can be computed. The RMDQ, in its Italian validation, showed levels of reliability and validity comparable to the original version [32]. Higher levels of pain-related disability are reflected by higher RMDQ scores.

We used the following questionnaire to measure the predictors:

- The Italian validation of Tampa Scale of Kinesiophobia (TSK) [33] was used to assess the level of kinesiophobia. The TSK includes 13 items on a four-point Likert scale ranging from "strongly disagree" to "strongly agree" [34]. The TSK has been validated for use in individuals affected by chronic LBP [16]. The Italian version of the TSK shows a good factorial structure and acceptable psychometric properties [33]. Total Score ranges from 17 to 68, with higher scores suggesting higher levels of kinesiophobia [33].

- The Italian validation of pain catastrophizing scale (PCS) [35] was used to assess the level of catastrophic thinking about pain. The PCS is composed of 13-items on a five-point Likert scale (from $0=$ "not at all" to $4=$ "all the time"), developed for both clinical and non-clinical populations. The Italian version shows good psychometric properties in agreement with the original version [35]. Total score ranges from 0 to 52; with higher scores suggesting higher levels of pain catastrophizing [35].

\subsection{Statistical Analysis}

Counts and percentages were used to describe categorical variables, whereas means and standard deviations were used to describe continuous variables. To evaluate the contribution of TSK score and PCS score to the variance of NPRS score and RMDQ score, two independent multiple hierarchical regression analyses were performed considering NPRS score (model 1) and RMDQ score (model 2) as dependent variables. In both models, confounding factors that likely affect main outcomes (pain intensity and pain-related disability), were included in the first block; PCS score and TSK score were included in the second block. Confounding factors in model 1 were: gender, age and BMI $[36,37]$. Confounding factors in model 2 were: gender, age, BMI [36,37] and NPRS scores [38]. $\Delta \mathrm{R}^{2}$ was used to evaluate the additional amount of variance in the dependent variables that was accounted for by the variables included in the second block. The analyses were performed using Jamovi (version 1.2) [39]. $p$-Values of less than 0.05 were considered statistically significant.

\section{Results}

\subsection{Participants Characteristics}

The sample consisted of 68 women and 38 men. The description of demographical and clinical factors, as well as the questionnaires scores, are reported in Table 1. 
Table 1. Demographic and clinical characteristics of the sample $(n=106)$

\begin{tabular}{lcc}
\hline & $\boldsymbol{n} \mathbf{( \% )}$ & Mean $\pm \mathbf{s d}$ \\
\hline Gender & & \\
Female & $68(64.2)$ & \\
Male & $38(35.8)$ & \\
Age & & $57.1 \pm 9.67$ \\
Body Mass Index $\left(\mathrm{kg} / \mathrm{m}^{2}\right)$ & $39.8 \pm 5.58$ \\
Numeric Pain Rating Scale (NPRS) & $6.15 \pm 2.45$ \\
Roland Morris Disability & $11.33 \pm 6.74$ \\
Questionnaire (RMDQ) & $29.9 \pm 7.96$ \\
Tampa Scale of Kinesiophobia (TSK) & $23.5 \pm 11.1$ \\
Pain Catastrophizing Scale (PCS) & & \\
\hline
\end{tabular}

Note. Descriptive statistics are frequencies and percentages for categorical variables and means $\pm \mathrm{sd}$ for continuous variables. NPRS range: 0-10, RMDQ range: 0-24, TSK range: 11-44 PCS range: 0-52. Abbreviations: $s d=$ standard deviation.

\subsection{Predictors of Pain Intensity}

The full model of gender, age, BMI, PCS score, and TSK score as predictors and NPRS scores as the dependent variable was statistically significant, $R^{2}=0.198, F(5,100)=4.94$, $p<0.001$. The inclusion of the PCS score and the TSK score explained about $18 \%$ additional variance $\left(\Delta \mathrm{R}^{2}=0.177\right)$, compared to the first block including only the confounding factors. Only the TSK score significantly predicted pain intensity (Table 2).

Table 2. Multivariable linear regression model examining the independent effect of demographic features and psychological components of kinesiophobia (TSK score) and pain catastrophizing (PCS score) on pain intensity (NPRS score)

\begin{tabular}{cccc}
\hline & B & 95\% CI & $p$-Value \\
\hline & Block 1: Confounding Factors & \\
\hline Age & -0.009 & $-0.06-0.04$ & 0.700 \\
\hline Gender & -0.524 & $-1.44-0.39$ & 0.259 \\
\hline BMI & -0.038 & $-0.04-0.12$ & 0.346 \\
\hline $\begin{array}{c}\text { Tampa Scale of } \\
\text { Kinesiophobia (TSK) }\end{array}$ & Block 2: Psychological variables & $<0.001$ * \\
\hline $\begin{array}{c}\text { Pain Catastrophizing } \\
\text { Scale (PCS) }\end{array}$ & 0.126 & $0.07-0.18$ & 0.528 \\
\hline
\end{tabular}

Note. Abbreviations: B = unstandardized beta; $\mathrm{CI}=$ confidence interval. TSK = Tampa Scale of Kinesiophobia; PCS = Pain Catastrophizing Scale; NPRS = Numeric Pain Rating Scale. ${ }^{*} p<0.05$

\subsection{Predictors of Pain-Related Disability}

The full model of gender, age, BMI, NPRS score, PCS score, and TSK score as predictors and RMDQ score as the dependent variable was statistically significant, $R^{2}=0.339$, $\mathrm{F}(6,99)=8.46, p<0.001$. The inclusion of the PCS score and the TSK score explained about $10 \%$ additional variance $\left(\Delta R^{2}=0.102\right)$, compared to the first block including only the confounding factors. It was found that TSK score significantly predicted the RMDQ score (Table 3). 
Table 3. Multivariable linear regression model examining the independent effect of demographic features and psychological components of kinesiophobia (TSK score) and pain catastrophizing (PCS score) on pain-related disability (RMDQ score)

\begin{tabular}{clcc}
\hline & B & 95\% CI & $p$-Value \\
\hline & Block 1: Confounding Factors & \\
\hline Age & 0.084 & $-0.03-0.20$ & 0.162 \\
\hline Sex & -1.424 & $-3.74-0.89$ & 0.226 \\
\hline BMI & -0.06 & $-0.26-0.14$ & 0.555 \\
\hline $\begin{array}{c}\text { Numeric Pain Rating } \\
\text { Scale (NPRS) }\end{array}$ & 0.741 & $0.24-1.23$ & 0.004 * \\
\hline $\begin{array}{c}\text { Tampa Scale of } \\
\text { Kinesiophobia (TSK) }\end{array}$ & Block 2: Psychological factors & $<0.001$ * \\
\hline $\begin{array}{c}\text { Pain Catastrophizing } \\
\text { Scale (PCS) }\end{array}$ & 0.298 & $0.13-0.46$ & 0.874 \\
\hline
\end{tabular}

Note. Abbreviations: $\mathrm{B}=$ unstandardized beta; $\mathrm{CI}=$ confidence interval. TSK = Tampa Scale of

Kinesiophobia; PCS = Pain Catastrophizing Scale; RMDQ = Roland-Morris Disability Questionnaire $* p<0.05$

\section{Discussion}

The study aimed to verify the role of kinesiophobia and pain catastrophizing in explaining pain intensity and pain-related disability in a sample of individuals with obesity and CLBP. According to the results, we observed that kinesiophobia, but not pain catastrophizing, significantly explained both the subjective levels of pain intensity and pain-related disability.

Kinesiophobia is a key component of the fear-avoidance model of chronic pain [19], and its pivotal role, in explaining pain intensity and disability, was previously supported in individuals affected by obesity and CLBP [40]. Kinesiophobia results from the misinterpretation of painful bodily sensations as a sign of serious injury. Consequently, individuals might tend to avoid pain-related movements driven by the emotion of fear, increasing disuse, and disability [41].

We might assume that obesity plays a central role in explaining the important role of kinesiophobia in our sample. Because of the associated pathologies like respiratory difficulty, greater movement difficulties and discomforts [42], individuals affected by obesity may develop greater aversion and fear of movement. Supporting this explanation, it has been previously reported by Vincent et al. [26] that adults affected by severe obesity and CLBP reported higher levels of kinesiophobia compared to their normal-weight counterparts [26]. Also, the same authors examined the relationships between LBP, kinesiophobia and disability in overweight, older adults with LBP [40], observing that the TSK score are significant predictors of LBP severity and perceived disability [40]. Interestingly, our study and those of Vincent and colleagues shared similar results, even though different ages were considered: indeed, although Vincent and colleagues studied an elderly population, our participants showed a wider age range.

Conversely, we reported that pain catastrophizing was not significantly associated with pain intensity and pain-related disability; these results seemed in disagreement with previous evidence $[20,38,43,44]$; nevertheless, previous research did not focus specifically on the population of individuals with obesity. Differently, our sample is composed predominantly of individuals with moderate and severe obesity.

This study has several limitations. First, it is a cross-sectional study: although a significant association has been found between kinesiophobia and both pain severity and pain-related disability, it is not possible to establish a causal relationship. Longitudinal studies will be necessary to confirm the hypothesis that maladaptive cognitions influ- 
ence the development and maintenance of pain and disability in individuals with CLBP and obesity. Secondly, the sample was composed exclusively of hospitalized individuals, which may induce a selection bias: thus, generalization to patients from different settings should be carefully done. Individuals with CLBP and obesity might have different coping mechanisms about pain in comparison with healthy weight individuals, that have not been considered in this study. For example, we have not included in the confounding factors the drug regimen of the subjects enrolled. It has been previously reported [26] that individuals with obesity reported a higher consumption of narcotic use to control pain symptoms compared to their normal-weight counterparts, suggesting that, in this specific population, drug use may be an avoidance coping strategy. Also, we did not assess the presence of emotional eating. Nevertheless, if in our sample emotional eating as a coping strategy of pain was predominant, this pattern would lead to positive energy balance and, ultimately, weight gain, obesity, and increased pain and disability, as suggested by a previous study [45].

On the other hand, this article has several strengths, which include the use of validated, reliable survey instruments, as well as an adequate sample size, and the fact that it presents data on a population on which there is still little research. Moreover, we assessed a clinical population (i.e., individuals with CBLP and obesity), about which very little evidence is reported in the literature.

Future research should investigate the role of kinesiophobia on pain intensity and pain-related disability in individuals with obesity, while also taking into account the role of physical exercise and physical therapy. Finally, given the aim of the study, in this work we did not take into account what was the primary medical condition (i.e., medical, psychological, socio-economical, and so on) which might have been contributed to obesity. In the future, it could be interesting to consider the determinants of obesity and their possible influence on kinesiophobia, pain intensity, and pain-related disability.

\section{Conclusions}

Psychological factors play an important role in pain management. Our study emphasizes the role of kinesiophobia in pain intensity and pain-related disability. This result could be a helpful tool to identify those individuals most at risk of developing a self-perception of negative functional ability. This might be crucial in designing rehabilitative programs to manage pain effectively. Moreover, kinesiophobia can be a useful therapeutic target to be included in interdisciplinary pain management interventions in individuals with obesity and chronic LBP.

Author Contributions: Conceptualization, G.V.; Methodology, G.V.; Formal analysis, G.V. and E.M.G.; Writing—original draft preparation, G.V.; Writing—review and editing, G.V., E.M.G., F.S., P.C., R.C., and G.C. All authors have read and agreed to the published version of the manuscript.

Funding: This research received no external funding.

Institutional Review Board Statement: The study was conducted according to the guidelines of the Declaration of Helsinki of 1975, as revised in 1983, and approved by the Ethics Committee of Istituto Auxologico Italiano (code 2020_02_18_04).

Informed Consent Statement: Informed consent was obtained from all subjects involved in the study.

Data Availability Statement: The data presented in this study are available on request from the corresponding author. The data are not publicly available due to their containing information that could compromise the privacy of research participants.

Conflicts of Interest: The authors declare no conflict of interest.

\section{References}

1. Haslam, D.W.; James, W.P. Obesity. Lancet 2005, 366, 1197-1209. [CrossRef]

2. Doll, H.A.; Petersen, S.E.; Stewart-Brown, S.L. Obesity and Physical and Emotional Well-Being: Associations between Body Mass Index, Chronic Illness, and the Physical and Mental Components of the SF-36 Questionnaire. Obes. Res. 2000, 8, 160-170. [CrossRef] [PubMed] 
3. Davison, K.K.; Ford, E.S.; Cogswell, M.E.; Dietz, W.H. Percentage of Body Fat and Body Mass Index Are Associated from NHANES III. J. Am. Geriatr. Soc. 2002, 50, 1802-1809. [CrossRef] [PubMed]

4. Giusti, E.M.; Spatola, C.; Brunani, A.; Kumbhare, D.; Oral, A.; Ilieva, E.; Kiekens, C.; Pietrabissa, G.; Manzoni, G.M.; Imamura, M.; et al. ISPRM/ESPRM Guidelines on Physical and Rehabilitation Medicine (PRM) professional practice for adults with obesity and related comorbidities. Eur. J. Phys. Rehabil. Med. 2020. In press.

5. Zhang, T.T.; Liu, Z.; Liu, Y.L.; Zhao, J.J.; Liu, D.W.; Tian, Q.B. Obesity as a Risk Factor for Low Back Pain: A Meta-Analysis. Clin. Spine Surg. 2018, 31, 22-27. [CrossRef]

6. International Association for the Study of Pain. Classification of Chronic Pain-Description of Chronic Pain Syndromes and Definitions of Pain Terms, 2nd ed.; Merskey, H., Ed, N.B., Eds.; IASP Press Seattle: Seattle, WA, USA, 2002; ISBN 0931092051.

7. Imes, C.C.; Burke, L.E. The Obesity Epidemic: The USA as a Cautionary Tale for the Rest of the World. Curr. Epidemiol. Rep. 2014, 1, 82-88. [CrossRef]

8. Urquhart, D.M.; Berry, P.; Wluka, A.E.; Strauss, B.J.; Wang, Y.; Proietto, J.; Jones, G.; Dixon, J.B.; Cicuttini, F.M.; Wang, Y.; et al. Increased Fat Mass Is Associated with High Levels of Low Back Pain Intensity and Disability. Spine 2011, 36, 1320-1325. [CrossRef]

9. Tukker, A.; Visscher, T.L.S.; Picavet, H.S.J. Overweight and health problems of the lower extremities: Osteoarthritis, pain and disability. Public Health Nutr. 2008, 12, 359-368. [CrossRef]

10. Janke, E.A.; Collins, A.; Kozak, A.T. Overview of the relationship between pain and obesity: What do we know? Where do we go next? J. Rehabil. Res. Dev. 2007, 44, 245-261. [CrossRef]

11. Amy, J.E.; Megan, F.; Christina, H.; Brittaniy, H.; Jessica, M.S.; Michelle, L.R. A randomized clinical trial of an integrated behavioral self-management intervention Simultaneously Targeting Obesity and Pain: The STOP trial. BMC Public Health 2014, 14, 621.

12. Scarpina, F.; Marzullo, P.; Mai, S.; Mauro, A.; Scacchi, M.; Costantini, M. Altered temporal sensitivity in obesity is linked to pro-inflammatory state. Sci. Rep. 2019, 9, 1-10. [CrossRef] [PubMed]

13. Amy, J.E.; Kozak, A.T. The more pain I have, the more I want to eat: Obesity in the context of chronic pain. Obesity 2012, 20, 2027-2034. [CrossRef] [PubMed]

14. Zdziarski, L.A.; Wasser, J.G.; Vincent, H.K. Chronic pain management in the obese patient: A focused review of key challenges and potential exercise solutions. J. Pain Res. 2015, 8, 63-77. [CrossRef] [PubMed]

15. Bushnell, M.C.; Čeko, M.; Low, L.A. Cognitive and emotional control of pain and its disruption in chronic pain. Nat. Rev. Neurosci. 2013, 14, 502-511. [CrossRef] [PubMed]

16. Vlaeyen, J.W.; Kole-Snijders, A.M.; Boeren, R.G.; van Eek, H. Fear of movement/(re) injury in chronic low back pain and its relation to behavioral performance. Pain 1995, 62, 363-372. [CrossRef]

17. Meulders, A. From fear of movement-related pain and avoidance to chronic pain disability: A state-of-the-art review. Curr. Opin. Behav. Sci. 2019, 26, 130-136. [CrossRef]

18. Vlaeyen, J.W.S.; Linton, S.J. Fear-avoidance and its consequences in chronic musculoskeletal pain: A state of the art. Pain 2000, 85, 317-332. [CrossRef]

19. Goossens, E.J.B.; Linton, S.J.; Crombez, G.; Leeuw, M.; Boersma, K.; Vlaeyen, J.W.S. The Fear-Avoidance Model of Musculoskeletal Pain: Current State of Scientific Evidence. J. Behav. Med. 2007, 30, 77-94. [CrossRef]

20. Giusti, E.M.; Manna, C.; Varallo, G.; Cattivelli, R.; Manzoni, G.M.; Gabrielli, S.; Amario, F.D.; Lacerenza, M.; Castelnuovo, G. The Predictive Role of Executive Functions and Psychological Factors on Chronic Pain after Orthopaedic Surgery: A Longitudinal Cohort Study. Brain Sci. 2020, 10, 685. [CrossRef]

21. Quartana, P.J.; Campbell, C.M.; Edwards, R. Pain catastrophizing: A critical review. Expert Rev. Neurother. 2010, 9, 745-758. [CrossRef]

22. Chaves, J.F.; Brown, J.M. Spontaneous Cognitive Strategies for the Control of Clinical Pain and Stress. J. Behav. Med. 1987, 10, 263-276. [CrossRef] [PubMed]

23. Larsson, C.; Hansson, E.E.; Sundquist, K.; Jakobsson, U. Kinesiophobia and its relation to pain characteristics and cognitive affective variables in older adults with chronic pain. BMC Geriatr. 2016, 1-7. [CrossRef] [PubMed]

24. Knapik, A.; Saulicz, E. Kinesiophobia-Introducing a New Diagnostic Tool by. J. Hum. Kinet. 2011, 28, 25-31. [CrossRef]

25. Linton, S.J.; Nordin, E. A 5-Year Follow-Up Evaluation of the Health and Economic Consequences of an Early Cognitive Behavioral Intervention for Back Pain: A Randomized, Controlled Trial. Spine 2006, 31, 853-858. [CrossRef] [PubMed]

26. Vincent, H.K.; Omli, M.R.; Day, T.; Hodges, M.; Vincent, K.R.; George, S.Z. Fear of Movement, Quality of Life, and Self-Reported Disability in Obese Patients with. Pain Med. 2011, 35, 154-164. [CrossRef]

27. Shelby, R.A.; Somers, T.J.; Keefe, F.J.; Pells, J.J.; Dixon, K.E.; Blumenthal, J.A. Domain Specific Self-Efficacy Mediates the Impact of Pain Catastrophizing on Pain and Disability in Overweight and Obese Osteoarthritis Patients. J. Pain 2008, 9, 912-919. [CrossRef]

28. Erdfelder, E.; Faul, F.; Buchner, A. Statistical power analyses using G* Power 3.1: Tests for correlation and regression analyses. Behav. Res. Methods 2009, 41, 1149-1160. [CrossRef]

29. World Health Organization. Obesity: Preventing and Managing the Global Epidemic. Report of a WHO Consultation on Obesity; Technical Report Series; World Health Organization: Geneva, Switzerland, 2000; ISBN 9241208945.

30. Institute for Clinical Systems Improvement. Adult Acute and Subacute Low Back Pain Diagnosis Algorithm; Institute for Clinical Systems Improvement: Bloomington, MN, USA, 2018.

31. Breivik, H.; Borchgrevink, P.C.; Allen, S.M.; Rosseland, L.A.; Romundstad, L.; Hals, E.K.B.; Kvarstein, G.; Stubhaug, A. Assessment of pain. Br. J. Anaesth. 2008, 101, 17-24. [CrossRef] 
32. Padua, L.; Ceccarelli, E.; Romanini, E.; Zanoli, G.; Bondì, R. Italian version of the Roland Disability Questionnaire, specific for low back pain: Cross-cultural adaptation and validation. Eur. Spine J. 2002, 11, 126-129. [CrossRef]

33. Monticone, M.; Giorgi, I.; Baiardi, P.; Barbieri, M.; Rocca, B.; Bonezzi, C. Development of the Italian Version of the Tampa Scale of Kinesiophobia (TSK-I): Cross-Cultural Adaptation, Factor Analysis, Reliability, and Validity. Spine 2010, 35, 1241-1246. [CrossRef]

34. Woby, S.R.; Roach, N.K.; Urmston, M.; Watson, P.J. Psychometric properties of the TSK-11: A shortened version of the Tampa Scale for Kinesiophobia. Pain 2005, 117, 137-144. [CrossRef] [PubMed]

35. Monticone, M.; Baiardi, P.; Ferrari, S.; Foti, C.; Mugnai, R.; Pillastrini, P.; Rocca, B.; Vanti, C. Development of the Italian version of the Pain Catastrophising Scale (PCS-I): Cross-cultural adaptation, factor analysis, reliability, validity and sensitivity to change. Qual. Life Res. 2012, 21, 1045-1050. [CrossRef] [PubMed]

36. Majedi, H.; Amini, M.H.; Yousefshahi, F.; Majedi, M.; Rahimi, M.; Orandi, A. Predicting Factors of Pain Duration in Patients with Chronic Pain: A Large Population-based Study. Anesth. Pain Med. 2020, 10, 1-6. [CrossRef]

37. Cimmino, M.A.; Ferrone, C.; Cutolo, M. Epidemiology of chronic musculoskeletal pain. Best Pract. Res. Clin. Rheumatol. 2011, 25, 173-183. [CrossRef] [PubMed]

38. Sanchis-alfonso, J.D.V.; Lo, L. Influence of kinesiophobia and catastrophizing on pain and disability in anterior knee pain patients Influence of kinesiophobia and catastrophizing on pain and disability in anterior knee pain patients. Knee Surg. Sport. Traumatol. Arthrosc. 2013, 21, 1562-1568. [CrossRef]

39. The Jamovi Project 2020. jamovi (version 1.2). Available online: https:/ /www.jamovi.org (accessed on 9 December 2020).

40. Vincent, H.K.; Seay, A.N.; Montero, C.; Conrad, B.P.; Hurley, R.W.; Vincent, K. Kinesiophobia and Fear Avoidance Beliefs in Overweight Older Adults with Chronic Low Back Pain, Relationship to Walking Endurance: Part II. Am. J. Phys. Med. Rehabil. 2014, 92, 439-445. [CrossRef] [PubMed]

41. Vlaeyen, J.W.S.; Kole-snijders, A.M.J.; Annemarie, M.; Ruesink, R.; Heuts, P.H.T.G. The Role of Fear of Movement/(Re) Injury in Pain Disability. J. Occup. Rehabil. 1995, 5, 235-252. [CrossRef]

42. Van der Hulst, M.; Vollenbroek-Hutten, M.M.; Rietman, J.S.; Schaake, L.; Groothuis-Oudshoorn, K.G.; Hermens, H. Back Muscle Activation Patterns in Chronic Low Back Pain During Walking: A “Guarding” Hypothesis. Clin. J. Pain 2010, 26, 30-37. [CrossRef]

43. Picavet, H.S.J.; Vlaeyen, J.W.S.; Schouten, J.S.A.G. Pain Catastrophizing and Kinesiophobia: Predictors of Chronic Low Back Pain. Am. J. Epidemiol. 2002, 156, 1028-1034. [CrossRef]

44. Giusti, E.M.; Lacerenza, M.; Manzoni, G.M.; Castelnuovo, G. Psychological and psychosocial predictors of chronic postsurgical pain: A systematic review and meta-analysis. Pain 2020, in press. [CrossRef]

45. Janke, E.A.; Jones, E.; Hopkins, C.M.; Ruggieri, M.; Hruska, A. Catastrophizing and anxiety sensitivity mediate the relationship between persistent pain and emotional eating. Appetite 2016, 103, 64-71. [CrossRef] [PubMed] 